\title{
VARIANCE COMPONENT ESTIMATES OF SOME BOAR SEMEN CHARACTERISTICS AND THEIR USE IN DESIGNING EXPERIMENTS*
}

\author{
J. J. LUGAS, B. W. PICKETT $\dagger$ AND R. J. KOMAREK \\ Storrs Agricultural Experiment Station, Storrs, Connecticut, U.S.A. \\ (Received 12th April 1967, revised 17th July 1967)
}

\begin{abstract}
Summary. Semen records of ten ejaculates from each of ten Yorkshire boars were used to estimate the boar and ejaculate variance components for eleven semen characteristics. These data were used to estimate the power of the test. In ten of eleven characteristics, a minimum of five boars and five ejaculates per boar provided at least a $90 \%$ chance of detecting a difference of $50 \%$ of the mean. For these same ten characteristics, a minimum of fourteen boars and forty-three ejaculates per boar provided at least a $90 \%$ chance of detecting a difference of $25 \%$ of the mean.
\end{abstract}

\section{INTRODUCTION}

Estimates of the magnitude of the variation resulting from the measurement of boar semen characteristics have not been found in the literature by the authors. In cases where this variation arises from more than one source, it is important to determine what portion of the total variation is contributed by each source. Estimates of the variance components for these sources may then be used to estimate the magnitude of error variance. The error variance estimate can be used to determine the size of an experiment (animals and number of observations per animal) required to detect a specified treatment difference at a specified level of significance $\left(P_{\mathrm{I}}\right)$, and with a specified probability $\left(1-P_{\mathrm{II}}=\right.$ the power of the test), of detecting the difference.

The purpose of this study was to obtain estimates of the variance components contributing to total variance of some boar semen characteristics, and to use these estimates to determine the size of future boar semen studies.

\section{MATERIALS AND METHODS}

Estimates of the variance components of seminal characteristics of ten ejaculates from each of ten Yorkshire boars were used in this study. The animals were 14 to 15 months of age and the collection interval was 6 days.

\footnotetext{
* Scientific contribution No. 240, Storrs Agricultural Experiment Station, University of Connecticut, Storrs.

$\dagger$ Present address: Animal Reproduction Laboratory, Colorado State University, Fort Collins, 80521.
} 
The two sources of variation considered in the variance component analysis and their expected mean squares are, boars $=\sigma_{\mathrm{E}}^{2}+k \sigma_{\mathrm{B}}^{2}$ and ejaculates within boars $=\sigma_{\mathrm{E}}^{2}$. Analytical error (samples within ejaculates) was not estimated in this study. The boar source was considered to be random and the ejaculate source to be random and nested within boar. The following linear model was considered to be appropriate for these data:

$$
X_{i j}=\mu+\beta_{i}+e_{i j}
$$

where $X_{i j}$ is the value of the $j$ th ejaculate from the $i$ th animal. In this model, $\mu$ is the population mean, $\beta_{i}$ and $e_{i j}$ components are assumed to be random variables normally and independently distributed with means zero and variances of $\sigma_{\mathrm{B}}^{2}$ and $\sigma_{\mathrm{E}}^{2}$, respectively.

The composition of the expected mean squares and the coefficient of the component $\sigma_{\mathrm{B}}^{2}$ were determined by the method of Henderson $(1953,1960)$.

In an experiment where treatments are applied to the boars, the mean square for boars $\left(\sigma_{\mathrm{E}}^{2}+k \sigma_{\mathrm{B}}^{2}\right)$ becomes the error term for testing treatment differences. The standard deviation of a treatment mean can then be estimated by:

$$
s_{\bar{x}}=\int\left(\frac{s_{\mathrm{E}}^{2}}{e b}+\frac{s_{\mathrm{B}}^{2}}{b}\right)
$$

where $s_{\mathrm{E}}^{2}$ is the ejaculate variance, $s_{\mathbf{B}}^{2}$ is the boar variance, $e$ is the number of ejaculates per boar and $b$ is the number of boars. For a two-treatment experiment, $P_{\mathrm{II}}$ was calculated by computing Tang's $\phi$ for these data. A modification of the expression shown by Kempthorne (1952) was used and is given by:

$$
\phi=\int\left(\frac{\Delta^{2}}{4 \sigma^{2}}\right)
$$

where $\Delta$ is the treatment difference to be detected and $\sigma$ is the standard deviation of a treatment mean. This is equivalent to the formula for calculating $\phi$ used by Hafs, Bratton, Henderson \& Foote (1958) and shown by Henderson (1960). After computing $\phi, P_{\mathrm{II}}$ was determined from Tang's tables of $\phi$ (Tang, 1938; Kempthorne, 1952).

The power of the analysis of variance $\mathrm{F}$ test $\left(1-P_{\mathrm{II}}\right)$ was estimated for some possible two-treatment experiments with varying numbers of boars and ejaculates per boar.

All computations were performed by an IBM 7040 computer at the University of Connecticut Computer Center. The techniques for determining these semen characteristics are described by Pickett, Komarek, Gebauer, Benson \& Gibson (1967).

\section{RESULTS AND DISGUSSION}

The ejaculate means, standard deviations and coefficients of variation for the eleven semen characteristics are shown in Table 1. The initial motilities of the ejaculates from one boar were all estimated at or near zero. The data from this boar for the other ten semen characteristics appeared normal and were in the same range as the values for the other nine boars. Therefore, estimates for initial motility were computed deleting this one boar. 


\section{TABLE 1}

EJACULATE MEANS, STANDARD DEVIATIONS, COEFFIGIENTS OF VARIATION AND VARIANCE COMPONENT ESTIMATES FOR BOAR SEMEN GHARACTERISTICS

\begin{tabular}{|c|c|c|c|c|c|}
\hline \multirow{2}{*}{ Characteristic } & \multirow{2}{*}{ Mean } & \multirow{2}{*}{$\begin{array}{l}\text { Standard } \\
\text { deviation }\end{array}$} & \multirow{2}{*}{$\begin{array}{c}\text { Coefficient } \\
\text { of } \\
\text { variation }\end{array}$} & \multicolumn{2}{|c|}{ Variance components } \\
\hline & & & & Boars & Ejaculates \\
\hline $\begin{array}{l}\text { Gel (g/ejac) } \\
\text { Gel-free semen }(\mathrm{ml} / \mathrm{ejac}) \\
\text { Sperm concentration }\left(10^{6} / \mathrm{ml}\right) \\
\text { Initial motility }(\%)^{*}\end{array}$ & $\begin{array}{r}52 \cdot 44 \\
323 \cdot 17 \\
315 \cdot 47 \\
87 \cdot 11\end{array}$ & $\begin{array}{l}26 \cdot 93 \\
77 \cdot 47 \\
81 \cdot 08 \\
12 \cdot 78\end{array}$ & $\begin{array}{l}51 \\
24 \\
26 \\
15\end{array}$ & $\begin{array}{r}474 \cdot 60 \\
2038 \cdot 63 \\
3433 \cdot 90 \\
41 \cdot 22\end{array}$ & $\begin{array}{r}293 \cdot 91 \\
4148 \cdot 26 \\
3447 \cdot 03 \\
126 \cdot 42\end{array}$ \\
\hline $\begin{array}{l}\text { Dry weight } \\
\text { Whole semen }(\%) \\
\text { Gel }(\mathrm{mg} / \mathrm{g}) \\
\text { Seminal plasma }(\mathrm{mg} / \mathrm{ml}) \\
\text { Spermatozoa }\left(\mu \mathrm{g} / 10^{6}\right)\end{array}$ & $\begin{array}{r}4 \cdot 63 \\
116 \cdot 94 \\
40 \cdot 77 \\
22 \cdot 42\end{array}$ & $\begin{array}{r}1 \cdot 04 \\
12 \cdot 42 \\
10 \cdot 26 \\
3 \cdot 04\end{array}$ & $\begin{array}{l}22 \\
11 \\
25 \\
14\end{array}$ & $\begin{array}{r}0 \cdot 57 \\
72 \cdot 38 \\
55 \cdot 53 \\
3 \cdot 89\end{array}$ & $\begin{array}{r}0 \cdot 57 \\
88 \cdot 36 \\
54 \cdot 73 \\
5 \cdot 74\end{array}$ \\
\hline $\begin{array}{l}\text { Lipid } \\
\text { Gel }(\mu \mathrm{g} / \mathrm{g}) \\
\text { Seminal plasma }(\mu \mathrm{g} / \mathrm{ml}) \\
\text { Spermatozoa }\left(\mu \mathrm{g} / 10^{6}\right)\end{array}$ & $\begin{array}{r}329 \cdot 27 \\
136 \cdot 03 \\
2 \cdot 25\end{array}$ & $\begin{array}{l}91.85 \\
33.93 \\
0.1749\end{array}$ & $\begin{array}{r}28 \\
25 \\
8\end{array}$ & $\begin{array}{r}2080.48 \\
221.44 \\
0.0032\end{array}$ & $\begin{array}{c}6612 \cdot 15 \\
950 \cdot 01 \\
0.0276\end{array}$ \\
\hline
\end{tabular}

* Based on nine boars with ten ejaculates per boar.

Table 1 shows the values of the variance component estimates for these data. The minimum numbers of boars and ejaculates per boar required to detect a treatment difference of $25 \%$ and $50 \%$ of the mean at the $5 \%$ level of significance with at least a $90 \%, 95 \%$ or $99 \%$ chance (power of the test $=1-P_{11}$ ) are shown in Table 2.

TABLE 2

MINIMUM NUMBER OF BOARS PER TREATMENT AND EJACULATES PER BOAR REQUIRED TO DETECT A TREATMENT DIFFERENGE OF $50 \%$ OR $25 \%$ OF THE MEAN WITH AT LEAST A $90 \%, 95 \%$ OR 99\% CHANCE AT THE $5 \%$ LEVEL OF SIGNIFICANCE

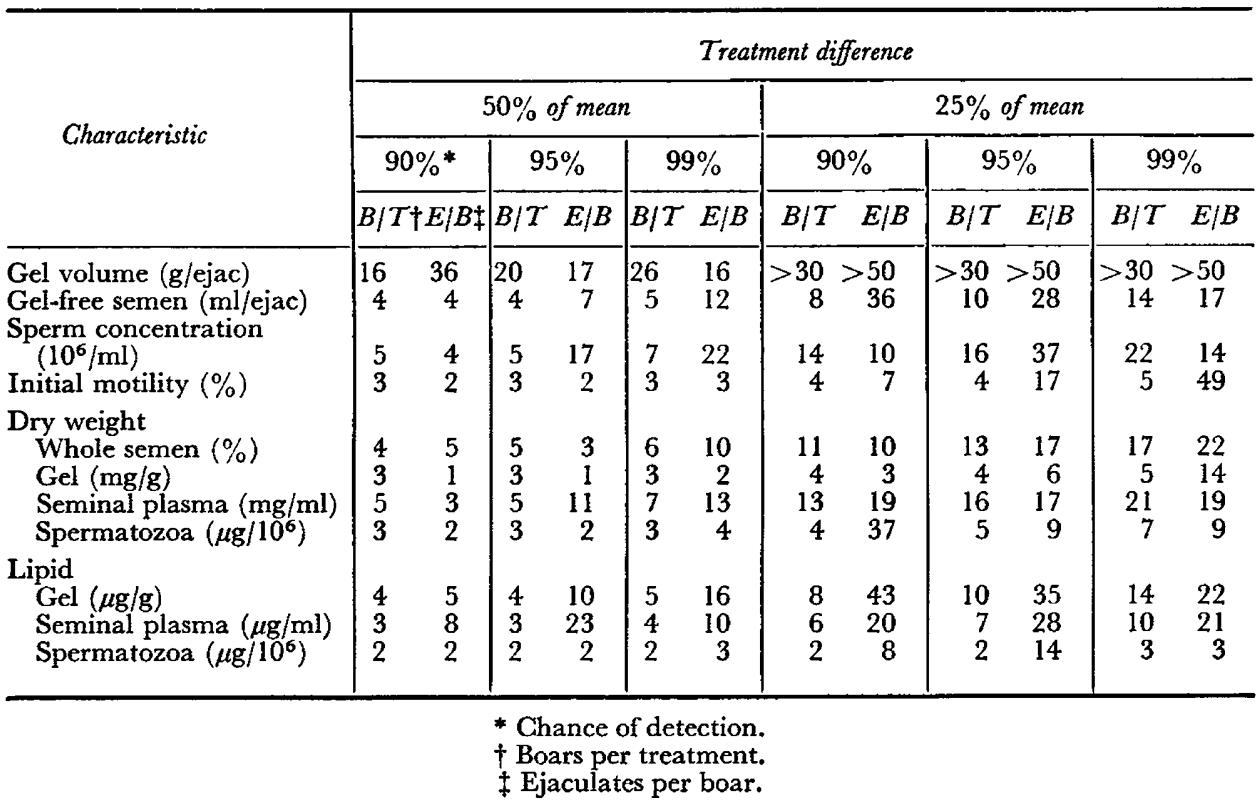


The low number of boars and ejaculates per boar required for initial motility, gel and spermatozoa dry weight, and lipid content of spermatozoa reflect the low coefficients of variation for these characteristics (Table 1). In all characteristics, except gel volume, a minimum of five boars and five ejaculates per boar provides at least a $90 \%$ chance of detecting a treatment difference of $50 \%$ of the mean. The high coefficient of variation for gel volume is reflected in the relatively high minimum number of boars (sixteen) and ejaculates per boar (thirty-six) required to provide at least a $90 \%$ chance of detecting a difference of $50 \%$ of the mean. To detect a difference of $25 \%$ of the mean, a minimum of fourteen boars and forty-three ejaculates per boar provides at least a $90 \%$ chance in all characteristics except gel volume. Even with thirty boars and fifty ejaculates per boar, gel volume does not provide a $90 \%$ chance of detecting a difference of $25 \%$ of the mean.

The alternatives available to the investigator for increasing the power $\left(1-P_{\mathrm{II}}\right)$ of the test include increasing the level of significance (using a $P_{\mathbf{1}}$ of $10 \%$ rather than $5 \%$ ), attempting to detect a larger difference, using more boars or ejaculates per treatment and/or reducing the mean square for error. The final choice of these alternatives is determined by the importance of the detectable difference and the resources the investigator has available.

\section{ACKNOWLEDGMENTS}

This investigation was supported in part by Public Health Research Grant GM 08738, from the National Institutes of Health, Division of General Medical Sciences. The computational part of this work was carried out at the Computer Center of the University of Connecticut, which is supported in part by Grant GP-1819 of the National Science Foundation.

\section{REFERENCES}

Hats, H. D., Bratton, R. W., Henderson, C. R. \& Foote, R. H. (1958) Estimation of some variance components of bovine semen criteria and their use in the design of experiments. 7 . Dairy Sci. 41, 96.

Henderson, C. R. (1953) Estimation of variance and covariance components. Biometrics, 9, 226.

Henderson, C. R. (1960) Techniques and procedures in animal production research, p. 1. American Society of Animal Production.

Kempthorne, O. (1952) The design and analysis of experiments, p. 219. Wiley, New York.

Pickett, B. W., Komarek, R. J., Gebauer, M. R., Benson, R. W. \& Gibson, E. W. (1967) Lipid and dry weight of ejaculated epididymal and post-castrate semen from boars. $\mathcal{J}$. Anim. Sci. 26, 792.

TANG, P. C. (1938) The power function of the analysis of variance tests with tables and illustrations of their use. Statist. Res. Mem. Univ. Coll. Lond. 2, 136. 